\title{
p16 Expression Correlates with Invasive Ocular Surface Squamous Neoplasms in HIV-Infected Mozambicans
}

\author{
Carla Carrilho ${ }^{a, b}$ Chau Miu ${ }^{c}$ Yeji Kim ${ }^{d}$ Susan Karkic Alexandra Balmacedac \\ Bindu Challac $^{c}$ Scott Diamond $^{\mathrm{e}}$ Eliane Monteiro $^{\mathrm{b}}$ Evelia Marole $^{\mathrm{g}}$ \\ Cesaltina Lorenzoni ${ }^{a}$ b, $f$ Yolanda Zambujog ${ }^{g}$ Yu-Tsueng Liu ${ }^{\mathrm{h}}$

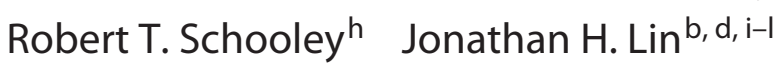 \\ a Department of Pathology, Eduardo Mondlane University, Maputo, Mozambique; bervice of Pathology, Maputo

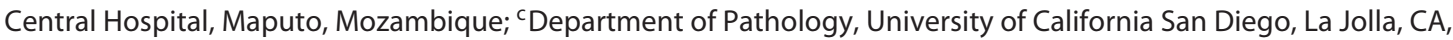 \\ USA; ${ }^{d}$ Department of Ophthalmology, University of California San Diego, La Jolla, CA, USA; 'Department of Pathology, \\ University of California Los Angeles, Los Angeles, CA, USA; ${ }^{f}$ Ministério da Saúde, Programa Nacional de Controlo \\ do Cancro, Maputo, Mozambique; ${ }^{9}$ Service of Ophthalmology, Maputo Central Hospital, Maputo, Mozambique; \\ h Department of Medicine, University of California San Diego, La Jolla, CA, USA; 'VA San Diego Healthcare System, San

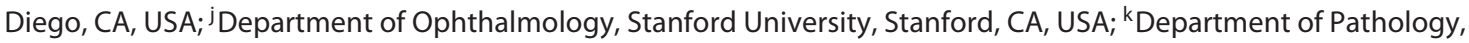 \\ Stanford University, Stanford, CA, USA; 'VA Palo Alto Healthcare System, Palo Alto, CA, USA
}

\section{Keywords}

Ocular surface squamous neoplasia $\cdot$ p16

immunohistochemistry $\cdot$ Human papillomavirus $\cdot$ HIV

\begin{abstract}
Background: p16 immunohistochemistry is widely used to diagnose human papillomavirus (HPV)-related squamous neoplasms of cervix, anogenital, head, and neck tissues. The incidence of these HPV-related squamous neoplasms is markedly increased in the HIV-infected population. Ocular surface squamous neoplasia (OSSN) is also more common in HIV-infected patients. However, the expression pattern of p16 in OSSN among HIV-infected patients is unclear. Here, we examined the expression of p16 in OSSN surgical excisions collected from a large HIV-infected cohort from Mozambique. Methods: OSSN surgical tissue specimens
\end{abstract}

\section{KARGER}

(c) 2019 S. Karger AG, Basel

E-Mail karger@karger.com

www.karger.com/oop were collected from 75 Mozambican patients. Formalinfixed, paraffin-embedded tissue blocks from these OSSNs were sectioned, stained with hematoxylin and eosin (H\&E), and p16 expression by immunohistochemistry. H\&E slides were reviewed to determine if OSSNs were noninvasive conjunctival intraepithelial neoplasms or invasive squamous cell carcinomas (SCC). Cases were classified as p16 positive or negative based on diffuse nuclear and cytoplasmic expression of p16 in neoplastic cells. Results: p16 positivity was found in a minority of OSSN cases (14/75). p16 positivity was significantly associated with the invasive SCC type of OSSN in HIV-infected patients ( $p$ value of 0.026). Conclusions: The majority of OSSNs in our HIV-infected cohort do not express p16. However, those cases that are p16-positive are significantly more likely to be the invasive SCC form of OSSN. We propose that $\mathrm{p} 16$ expression may identify more aggressive OSSNs in HIV-infected populations.

(c) 2019 S. Karger AG, Basel

Jonathan H. Lin, MD, PhD

School of Medicine, UC San Diego

9500 Gilman Dr MC0612

La Jolla, CA 92093-0612 (USA)

E-Mail JLin@ucsd.edu 


\section{Introduction}

Ocular surface squamous neoplasia (OSSN) arises from malignant transformation of the keratinocytes within the squamous epithelia of the conjunctiva and cornea, the anterior ocular surface tissues. OSSN is the most common ocular surface tumor with an incidence of 0.02 3.5 per 100,000 worldwide [1-3]. OSSNs can be histologically and prognostically classified into conjunctival intraepithelial neoplasia (CIN) and invasive squamous cell carcinoma (SCC). In CIN, the malignant keratinocytes are confined in the ocular surface epithelium, while in invasive SCC, the tumor cells have penetrated the basement membrane and invaded the substantia propria underlying the epithelium [4]. Invasive SCC has substantially worse prognosis than CIN due to increased metastasis and recurrence of SCCs arising from ocular surface [5].

Human papillomavirus (HPV), especially the highrisk HPV16 and HPV18 genotypes, causes squamous cell dysplasia and carcinoma arising from cervix, head, and neck squamous epithelia. HIV infection significantly increases the risk for developing these HPV-associated carcinomas [6], most likely due to host immunosuppression $[7,8]$. OSSNs are also significantly more prevalent in HIV-infected populations with some studies having shown HIV-positive individuals to have between 3- and 30-fold increased risk of developing OSSN [7]. Some studies have suggested that HPV is involved in the development of squamous lesions of the ocular surface [9-13]. However, other OSSN studies have not found evidence for HPV infection [14-16]. When looking at HPV prevalence in OSSN specifically, previous studies noted a highly variable rate ranging from 0 to $100 \%$ with an average prevalence rate of $33.8 \%$ [17]. Therefore, the role of HPV in OSSN pathogenesis is unresolved. Similarly, the role of HPV specifically in OSSNs arising in HIV-infected individuals is also unclear [16, 18-20].

p16 is a protein whose expression is strongly induced by HPV in cervical and head and neck squamous carcinomas $[21,22]$. p16 expression can be readily detected in tissues by immunohistochemical approaches [23], and p16-positive immunohistochemical reactivity is widely used as a biomarker to identify HPV in cervical, head and neck squamous neoplasms. Here, we performed immunohistochemical staining on OSSNs obtained from a large cohort of HIV-infected individuals to determine if $\mathrm{p} 16$ was induced in these squamous neoplasms.

\section{Material and Methods}

Patient Identification, Tissue Collection, and OSSN Diagnoses

Sixty-three HIV-infected and $12 \mathrm{HIV}$-uninfected patients with OSSNs underwent surgical excisions for their lesions at Maputo Central Hospital, Mozambique from 2014 to 2017 (Fig. 1). Tissues from these surgeries were processed in the Department of Pathology at Maputo Central Hospital, by $10 \%$ formalin fixation to generate paraffin-embedded tissue blocks. Hematoxylin and eosinstained $4-\mu \mathrm{m}$ sections from these tissue blocks were evaluated microscopically to identify OSSNs in the surgical excisions and to determine CIN or invasive SCC classification. Three pathologists at the University of California, San Diego, then reviewed each case as a group and came to a consensus in interpreting the stained specimens.

\section{p16 Immunohistochemistry}

Immunohistochemical studies for p16 were performed using a Ventana Benchmark Ultra as previously described [24]. A monoclonal mouse antibody (clone JC8; Santa Cruz Biotechnology; dilution 1:80) was used as the p16 antibody. Cervical SCC was used as a positive control for the p16 immunohistochemical studies (Fig. 2f). Lesions were scored as positive for p16 when both cytoplasmic and nuclear diffuse staining was observed in keratinocytes (Fig. 2e) [25-27]. Negative OSSNs showed no p16 expression (Fig. 2d). Sections were also counterstained to visualize nuclei.

\section{Statistical Analysis}

The association between p16 and OSSN classification (CIN vs. invasive SCC) were evaluated using Fisher's exact test. Mean age between gender, OSSN subgroups, and HIV status were evaluated using Mann-Whitney $\mathrm{U}$ test. R statistical software, version 3.5.1 was used for all statistical analyses. All statistical testing was two-sided, and a $p$ value $<0.05$ was considered statistically significant.

\section{Results}

A total of 75 patients with a mean age of 39.8 (range 21-67 years) were included in this study. Sixty-three (84\%) patients were HIV-infected and 12 (16\%) were not infected with HIV. The mean age was 40.9 (range 23-69 years) for the HIV-positive group and 39.6 (range 21-67 years) for the HIV-negative group. There were 28 males and 47 females in this study; 23 males and 40 females in the HIV-positive group and 5 males and 7 females in the HIV-negative group (Table 1). Ocular surface lesions were surgically removed from these patients and sent for histopathologic processing and diagnosis.

In 2 of the cases $(2 / 75$ or $3 \%)$, the histopathology did not show malignant cells, and instead the specimens revealed normal ocular surface conjunctiva consisting of a thin layer of squamous mucosal epithelium separated 
Fig. 1. Clinical photographs of 2 different patients with ocular surface squamous lesions prior to surgical excision.
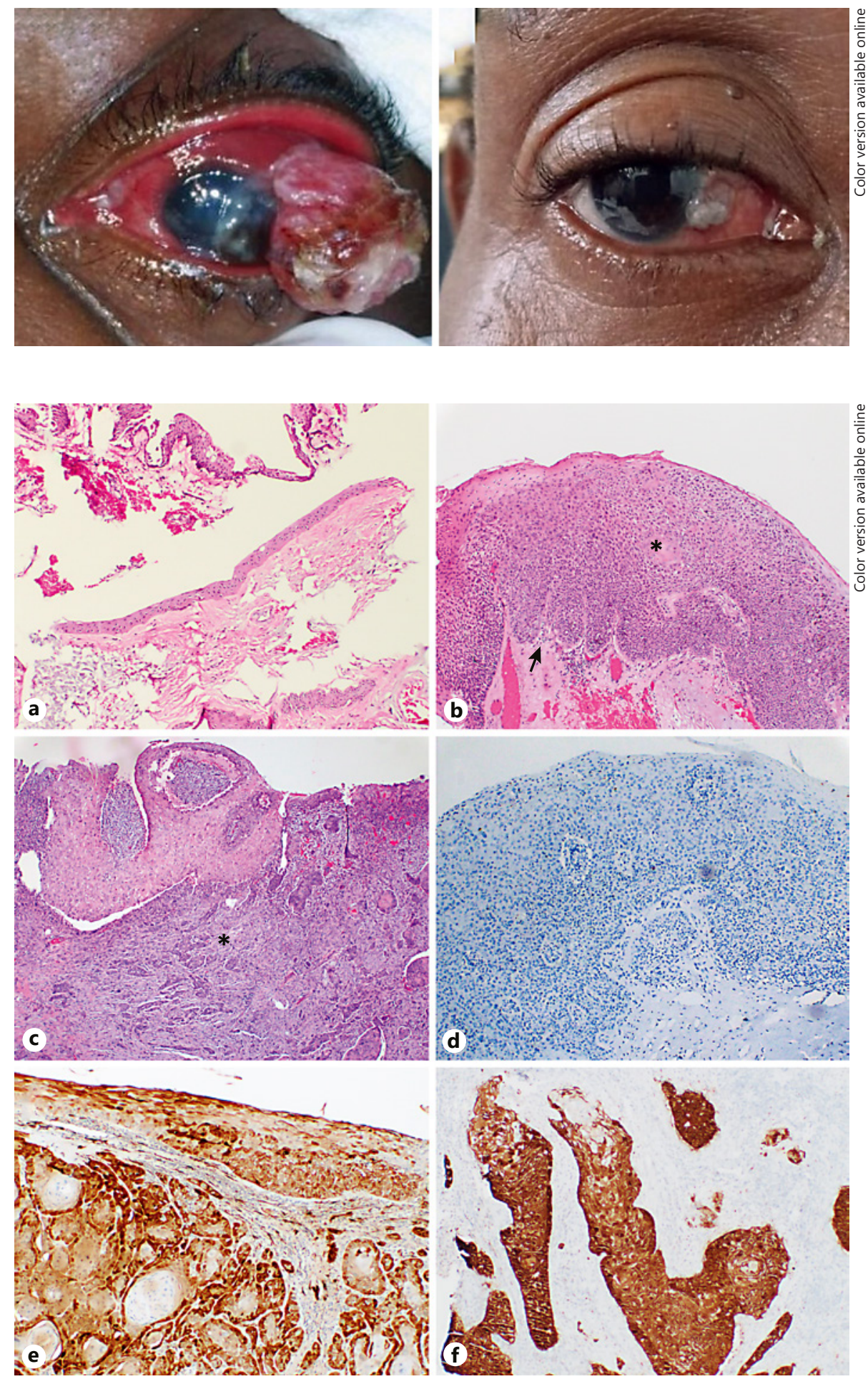

Fig. 2. Ocular surface squamous lesions with p16 immunohistochemistry staining. a Normal conjunctiva overlying substantia propria with solar damage (H\&E stain, plasia with abnormal cancer cells $\left(^{*}\right)$ within the epithelium and not penetrating basement membrane into substantia propria (black arrow) (H\&E stain, $\times 10)$. c Invasive squamous cell carcinoma with abnormal cancer cells $\left({ }^{*}\right)$ infiltrating lamina propria $\mathrm{H} \& \mathrm{E}$ stain $(\mathrm{H} \& \mathrm{E}$ stain, $\times 4)$. p16-negative OSSN (d) and diffuse p16-positive OSSN (brown staining) (e) compared to diffuse p16-positive cervical SCC staining (f) used as control. sistent with CIN form of OSSN with malignant keratinocytes present throughout the epithelium but with no invasion through the basement membrane into subepithelial structures (Fig. 2b; Table 1). The remaining 51 cases $(51 / 75$ or $68 \%)$ showed extensive infiltration of malignant 
Table 1. Summary of ocular surface excisions

\begin{tabular}{lccc}
\hline & All $(n=75)$ & HIV uninfected $(n=12)$ & HIV infected $(n=63)$ \\
\hline Age range, years & $21-67$ & $23-59$ & $21-67$ \\
Age, average (SD), years & $39.8(9.9)$ & $40.9(13.1)$ & $39.6(9.2)$ \\
Male:female & $28: 47$ & $5: 7$ & $23: 40$ \\
CIN & 22 & 5 & 17 \\
SCC & 51 & 6 & 45 \\
Benign ocular surface (pterygia) & 2 & 1 & 1 \\
P16+ immunohistochemistry & 14 & 2 & 12 \\
P16- immunohistochemistry & 61 & 10 & 51 \\
\hline
\end{tabular}

CIN, conjunctival intraepithelial neoplasia; SCC, squamous cell carcinoma.

Table 2. Summary of p16 immunohistochemistry expression in patients diagnosed with ocular surface squamous neoplasia

\begin{tabular}{lcll}
\hline & All $(n=73)$ & HIVuninfected $(n=11)$ & HIV infected $(n=62)$ \\
\hline CIN P16+ immunohistochemistry & 1 & 1 & 0 \\
CIN P16- immunohistochemistry & 21 & 4 & 17 \\
\hline SCC P16+ immunohistochemistry & 13 & 1 & 12 \\
SCC P16- immunohistochemistry & 38 & 5 & 33 \\
\hline
\end{tabular}

CIN, conjunctival intraepithelial neoplasia; SCC, squamous cell carcinoma.

keratinocytes past the basement membrane into subepithelial tissues, which were consistent with histopathologic features of invasive SCC (Fig. 2c; Table 1).

Additional tissue sections from all 75 ocular surface specimens were subsequently collected and stained for p16 immunoreactivity. In 61 specimens (61/75 or $81 \%)$, no p16 staining was seen (Fig. 2d; Table 1). The remaining 14 specimens (14/75 or 19\%) showed strong diffuse p16 immunoreactivity in the malignant cells (brown staining in Fig. 2e; Table 1). When broken down by OSSN subtypes, only 1 of the CIN cases (1/22 or $5 \%$ ) was p16 positive, while 13 of the invasive SCC cases (13/51 or $26 \%$ ) were p16 positive (Table 2). Within the $63 \mathrm{HIV}$ infected patients, 17 were diagnosed with CIN (17/63 or $27 \%)$ and 45 were diagnosed with invasive SCC (45/63 or $71 \%$; Table 2). Of these $17 \mathrm{HIV}$-infected CIN patients, none were p16 positive $(0 / 17$ or $0 \%)$, while 12 (12/45 or $27 \%$ ) were p16 positive in the invasive SCC HIV-infected subgroup (Table 2).

There was a weak non-statistically significant association between p16-positive immunohistochemistry and the presence of invasion of OSSN ( $p$ value of 0.051 ). The association became statistically significant in the HIV-in- fected group ( $p$ value of 0.026 ). There was no association between p16 positivity and OSSN in the HIV uninfected group. Mean age was not statistically associated with p16 immunopositivity, HIV infection, or OSSN subtype. Likewise, gender was not statistically associated with any of these factors.

\section{Discussion}

p16 overexpression is an established biomarker for $\mathrm{HPV}$-associated squamous neoplasms in cervix, head, and neck cancer [6-8]. However, little is known about the role of p16 in OSSN from HIV-infected patients. In our study, we found that a minority of OSSNs from infected patients showed p16 positivity. However, in this subset, we identified a statistically significant association between p16 positivity and invasive SCC of OSSNs in HIV-infected patients. Our results suggest that p16 expression identifies more aggressive OSSNs in HIV-infected patients.

The exact mechanism of increased p16 expression in our subset of OSSNs is unclear. HPV has been detected using a wide variety of methods, including p16 immu- 
nohistochemistry, in OSSN case series [9]. Some studies showed a perfect correlation between HPV positivity and OSSN $[28,29]$. However, others failed to detect evidence for HPV in patients with OSSN $[15,19]$. Similar to the findings in our current study, Woods et al. [9] detected HPV by p16 immunostaining in only a small fraction of their OSSN patients, but, similar to our findings, of those positive cases, all were SCCs of the conjunctiva. Furthermore, Chauhan et al. [22] found that p16 expression was significantly increased from early to advanced OSSN tumors staged. Although p16 induction is not exclusively linked to HPV infection, these studies coupled with our current results, suggest that HPV could contribute to more invasive OSSN [30]. However, additional studies are required to determine if the higher prevalence of p16 expression found in SCCs of the ocular surface reflects HPV infection in OSSNs.

Several studies have indicated that HIV infection increases the risk of OSSN $[10,31]$. Our current study could not demonstrate whether OSSN risk was increased due to HIV because we did not have sufficient control cases without OSSN $(2 / 75$ or $3 \%)$ to make that comparison. However, of the samples we studied, a high prevalence (84\%) of HIV-positive cases was detected which is much higher than the prevalence rate of HIV in Mozambique, which is $12.5 \%$ in adults aged $15-49$ [32]. Other studies have also shown similar results, where a significant percentage of OSSN patients in Africa were HIV positive [10, 31, 33].

While p16 overexpression and HIV have been studied extensively in cervical and oropharyngeal cancers and some studies investigated HIV and HPV individually as risk factors of OSSN, few have looked at the risk of OSSN in patients that are both HPV and HIV positive $[8,17,34-38]$. Even fewer studies stratified OSSN into CIN and invasive SCC, the noninvasive and invasive stages of OSSN, to study potential risk factor differences between the two. Of the few studies, AteenyiAgaba et al. [31] looked at the risk of OSSN between mucosal and cutaneous HPV in HIV-positive cases and found that positivity for cutaneous HPV types was not only associated with significantly increased risks for OSSN but also a significant increase in the ORs for OSSN between patients who were positive for both HIV and cutaneous HPV versus those infected with HIV only.

Our study suggests that positivity for p16 immunohistochemistry is not associated with the whole spectrum of OSSN but is more common in invasive SCC, and this as- sociation increases significantly in HIV-infected patients. p16 immunohistochemistry may be a useful bioassay in this population in cases where the evaluation of invasion is confounded by superficial sampling.

While increased p16 expression is linked to HPV infection in squamous neoplasms of the cervix, head, and neck, we note that HPV infection has not been universally found in squamous neoplasms of the ocular surface, and many other etiologies such as inflammation, radiation, or genomic damage can also induce p16 expression [39-41]. Future studies should investigate the mechanisms that trigger p16 expression in a subset of OSSNs.

\section{Acknowledgements}

We thank Dr. Vivian Snyder for her help in this study.

\section{Statement of Ethics}

The study protocol was approved by the University of California, San Diego, Institutional Review Board as well as the Mozambican National Committee for Bioethics and Health. The described research adhered to the tenets of the Declaration of Helsinki. The authors have no ethical conflicts to disclose.

\section{Disclosure Statement}

The authors have no conflicts of interest to declare.

\section{Funding Sources}

This research is supported by UCSD Cancer Center (NIH/NCI P30 CA23100) and Center for AIDS Research (NIAID P30 AI36214) HIV associated malignancy pilot grant, and also by P30EY022589 Core grant funding.

\section{References}

Ocul Oncol Pathol 2020;6:123-128 127

1 Grossniklaus HE, Green WR, Luckenbach M, Chan CC. Conjunctival lesions in adults. A clinical and histopathologic review. Cornea. 1987;6(2):78-116.

2 McClellan AJ, McClellan AL, Pezon CF, Karp CL, Feuer W, Galor A. Epidemiology of Ocular Surface Squamous Neoplasia in a Veterans Affairs Population. Cornea. 2013 Oct;32(10) 1354-8.

3 Di Girolamo N. Association of human papilloma virus with pterygia and ocular-surface squamous neoplasia. Eye (Lond). $2012 \mathrm{Feb}$ 26(2):202-11. 
4 Lee GA, Hirst LW. Ocular surface squamous neoplasia. Surv Ophthalmol. 1995 May-Jun; 39(6):429-50.

5 McKelvie PA, Daniell M, McNab A, Loughnan M, Santamaria JD. Squamous cell carcinoma of the conjunctiva: a series of 26 cases. Br J Ophthalmol. 2002 Feb;86(2):168-73.

6 Gichuhi S, Ohnuma S, Sagoo MS, Burton MJ. Pathophysiology of ocular surface squamous neoplasia. Exp Eye Res. 2014 Dec;129:172-82.

7 Rathi SG, Ganguly Kapoor A, Kaliki S. Ocular surface squamous neoplasia in HIV-infected patients: current perspectives. HIV AIDS (Auckl). 2018 Mar;10:33-45.

8 Carreira H, Coutinho F, Carrilho C, Lunet N. HIV and HPV infections and ocular surface squamous neoplasia: systematic review and meta-analysis. Br J Cancer. 2013 Oct;109(7): 1981-8.

9 Woods M, Chow S, Heng B, Glenn W, Whitaker N, Waring D, et al. Detecting human papillomavirus in ocular surface diseases. Invest Ophthalmol Vis Sci. 2013 Dec;54(13):8069-78.

10 Waddell KM, Lewallen S, Lucas SB, AtenyiAgaba C, Herrington CS, Liomba G. Carcinoma of the conjunctiva and HIV infection in Uganda and Malawi. Br J Ophthalmol. 1996 Jun;80(6):503-8.

11 McDonnell JM, McDonnell PJ, Sun YY. Human papillomavirus DNA in tissues and ocular surface swabs of patients with conjunctival epithelial neoplasia. Invest Ophthalmol Vis Sci. 1992 Jan;33(1):184-9.

12 McDonnell JM, Mayr AJ, Martin WJ. DNA of human papillomavirus type 16 in dysplastic and malignant lesions of the conjunctiva and cornea. N Engl J Med. 1989 Jun;320(22): $1442-6$.

13 Carrilho C, Gouveia P, Yokohama H, Lopes JM, Lunet N, Ferro J, et al. Human papillomaviruses in intraepithelial neoplasia and squamous cell carcinoma of the conjunctiva: a study from Mozambique. Eur J Cancer Prev. 2013 Nov;22(6):566-8.

14 Ateenyi-Agaba C, Weiderpass E, Tommasino M, Smet A, Arslan A, Dai M, et al. Papillomavirus infection in the conjunctiva of individuals with and without AIDS: an autopsy series from Uganda. Cancer Lett. 2006 Jul;239(1): 98-102.

15 Guthoff R, Marx A, Stroebel P. No evidence for a pathogenic role of human papillomavirus infection in ocular surface squamous neoplasia in Germany. Curr Eye Res. 2009 Aug; 34(8):666-71.

16 Newton R, Ziegler J, Ateenyi-Agaba C, Bousarghin L, Casabonne D, Beral V, et al.; Uganda Kaposi's Sarcoma Study Group. The epidemiology of conjunctival squamous cell carcinoma in Uganda. Br J Cancer. 2002 Jul;87(3): 301-8.

17 Chalkia AK, Bontzos G, Spandidos DA, Detorakis ET. Human papillomavirus infection and ocular surface disease (Review) [Review]. Int J Oncol. 2019 May;54(5):1503-10.

18 Moubayed P, Mwakyoma H, Schneider DT. High frequency of human papillomavirus $6 / 11,16$, and 18 infections in precancerous lesions and squamous cell carcinoma of the conjunctiva in subtropical Tanzania. Am J Clin Pathol. 2004 Dec;122(6):938-43.

19 Eng HL, Lin TM, Chen SY, Wu SM, Chen WJ. Failure to detect human papillomavirus DNA in malignant epithelial neoplasms of conjunctiva by polymerase chain reaction. Am J Clin Pathol. 2002 Mar;117(3):429-36.

20 Nakamura Y, Mashima Y, Kameyama K, Mukai M, Oguchi Y. Detection of human papillomavirus infection in squamous tumours of the conjunctiva and lacrimal sac by immunohistochemistry, in situ hybridisation, and polymerase chain reaction. Br J Ophthalmol. 1997 Apr;81(4):308-13.

21 Romagosa C, Simonetti S, López-Vicente L, Mazo A, Lleonart ME, Castellvi J, et al. p16(Ink4a) overexpression in cancer: a tumor suppressor gene associated with senescence and high-grade tumors. Oncogene. 2011 May; 30(18):2087-97.

22 Chauhan S, Sen S, Sharma A, Kashyap S, Tandon R, Bajaj MS, et al. p16INK4a overexpression as a predictor of survival in ocular surface squamous neoplasia. Br J Ophthalmol. 2018 Jun;102(6):840-7.

23 Lewis JS Jr. p16 Immunohistochemistry as a standalone test for risk stratification in oropharyngeal squamous cell carcinoma. Head Neck Pathol. 2012 Jul;6(S1 Suppl 1):S75-82.

24 Kobalka PJ, Abboud JP, Liao X, Jones K, Lee BW, Korn BS, et al. p16INK4A expression is frequently increased in periorbital and ocular squamous lesions. Diagn Pathol. 2015 Sep; 10(1): 175

25 Sano T, Oyama T, Kashiwabara K, Fukuda T, Nakajima T. Expression status of p16 protein is associated with human papillomavirus oncogenic potential in cervical and genital lesions. Am J Pathol. 1998 Dec;153(6):1741-8.

26 Shrestha T, Choi W, Kim GE, Yang JM, Yoon KC. Human papilloma virus identification in ocular surface squamous neoplasia by p16 immunohistochemistry and DNA chip test: A strobe-compliant article. Medicine (Baltimore). 2019 Jan;98(2):e13944-13944.

27 Singhi AD, Westra WH. Comparison of human papillomavirus in situ hybridization and p16 immunohistochemistry in the detection of human papillomavirus-associated head and neck cancer based on a prospective clinical experience. Cancer. 2010 May;116(9):2166-73.

28 Scott IU, Karp CL, Nuovo GJ. Human papillomavirus 16 and 18 expression in conjunctival intraepithelial neoplasia. Ophthalmology. 2002 Mar; 109(3):542-7.

29 Kuo KT, Chang HC, Hsiao CH, Lin MC. Increased Ki-67 proliferative index and absence of P16INK4 in CIN-HPV related pathogenic pathways different from cervical squamous intraepithelial lesion. Br J Ophthalmol. 2006 Jul;90(7):894-9.

30 Khleif SN, DeGregori J, Yee CL, Otterson GA, Kaye FJ, Nevins JR, et al. Inhibition of cyclin D-CDK4/CDK6 activity is associated with an E2F-mediated induction of cyclin kinase inhibitor activity. Proc Natl Acad Sci USA. 1996 Apr;93(9):4350-4.

31 Ateenyi-Agaba C, Franceschi S, WabwireMangen F, Arslan A, Othieno E, Binta-Kahwa $J$, et al. Human papillomavirus infection and squamous cell carcinoma of the conjunctiva. Br J Cancer. 2010 Jan;102(2):262-7.

32 UNAIDS. Mozambique, 2019.

33 Reynolds JW, Pfeiffer ML, Ozgur O, Esmaeli B. Prevalence and Severity of Ocular Surface Neoplasia in African Nations and Need for Early Interventions. J Ophthalmic Vis Res. 2016 Oct-Dec;11(4):415-21.

34 Beachler DC, D'Souza G. Oral HPV infection and head and neck cancers in HIV-infected individuals. Curr Opin Oncol. 2013 Sep; 25(5):503-10.

35 Cameron JE, Hagensee M. HPV-Associated Oropharyngeal Cancer in the HIV/AIDS Patient. In: Meyers C, editor. HIV/AIDS-Associated Viral Oncogenesis. Cham: Springer International Publishing; 2019. pp. 131-81.

36 De Vuyst H, Ndirangu G, Moodley M, Tenet V, Estambale B, Meijer CJ, et al. Prevalence of human papillomavirus in women with invasive cervical carcinoma by HIV status in Kenya and South Africa. Int J Cancer. 2012 Aug; 131(4):949-55.

37 Sahasrabuddhe VV, Mwanahamuntu MH, Vermund SH, Huh WK, Lyon MD, Stringer JS, et al. Prevalence and distribution of HPV genotypes among $\mathrm{HIV}$-infected women in Zambia. Br J Cancer. 2007 May;96(9):1480-

38 Vianna LM, Carneiro FP, Amorim R, Guerra EN, Cavalcanti Neto FF, Tiziani V, et al. Oropharynx HPV status and its relation to HIV infection. PeerJ. 2018 Mar;6:e4407.

39 Witkiewicz AK, Knudsen KE, Dicker AP, Knudsen ES. The meaning of p16(ink4a) expression in tumors: functional significance, clinical associations and future developments. Cell Cycle. 2011 Aug;10(15):2497503

40 Furth EE, Gustafson KS, Dai CY, Gibson SL, Menard-Katcher P, Chen T, et al. Induction of the tumor-suppressor p16(INK4a) within regenerative epithelial crypts in ulcerative colitis. Neoplasia. 2006 Jun;8(6):429-36.

41 Shao L, Feng W, Li H, Gardner D, Luo Y, Wang Y, et al. Total body irradiation causes long-term mouse BM injury via induction of HSC premature senescence in an Ink4a- and Arf-independent manner. Blood. 2014 May; 123(20):3105-15. 